\title{
PERBANDINGAN STRATEGI PEMASARAN PRODUK ANTARA HOKKYMART DAN BOLLYMART KOTA BIMA
}

\author{
Kurniawati'; Amirul Mukminin² \\ Program Studi Manajemen, STIE Bima, Nusa Tenggara Barat, Indonesia ${ }^{1,2}$. \\ Email.: kurniawati.stiebima@gmail.com ${ }^{1}$; amirul.stiebima@gmail.com²
}

\begin{abstract}
ABSTRAK
Penelitian ini menggunakan metode deskriptif kuantitatif dengan sumber data primer. Adapun tujuan dari penelitian ini adalah untuk mengetahui, membuktikan, dan menganalisis perbedaan strategi pemasaran pada Hokkymart, dan Bollymart. Populasi dalam penelitian ini yaitu keseluruhan konsumen yang berbelanja di Hokkymart, dan Bollymart. Sampel yang diambil sebanyak 100 orang responden dengan teknik accidental sampling. Pengumpulan data dilakukan dengan penyebaran kuesioner dengan skala likert. Teknik analisis data yang digunakan adalah analisis deskriptif komparatif Paired Varian dengan alat analisis yang digunakan adalah Statistical Package for the Social Sciences (SPSS) versi 23.0. Hasil penelitian menunjukan bahwa Terdapat perbedaan antara strategi pemasaran produk dengan nilai rata-rata (mean) variabel strategi pemasaran pada Hokkymart Kota Bima adalah sebesar 43,73. Sedangkan nilai rata-rata (mean) untuk variabel Bollymart Kota Bima adalah sebesar 51,76. Dari kedua variabel X1 dan X2 tersebut diperoleh nilai rata-rata Strategi Pemasaran Produk Bollymart Kota Bima lebih besar dari pada Strategi Pemasaran Produk pada Hokkymart Kota Bima.
\end{abstract}

Kata Kunci : Strategi Pemasaran

\section{Abstract}

This study uses a quantitative descriptive method with primary data sources. The purpose of this study is to find out, prove, and analyze the differences in marketing strategies at Hokkymart and Bollymart. The population in this study are all consumers who shop at Hokkymart and Bollymart. Samples were taken as many as 100 respondents with accidental sampling technique. Data was collected by distributing questionnaires with a Likert scale. The data analysis technique used is descriptive comparative analysis of paired variance with the analytical tool used is the Statistical Package for the Social Sciences (SPSS) version 23.o. The results showed that there was a difference between the product marketing strategy and the average value (mean) of the marketing strategy variable at Hokkymart Bima City was 43.73. While the average value (mean) for the variable Bollymart Bima City is 51.76. From the two variables X1 and X2, the average value of the Bollymart Product Marketing Strategy in Bima City is greater than the Product Marketing Strategy at the Bima City Hokkymart.

Keywords: Marketing Strategy

Diterima: 11 September 2021; Direvisi: 30 September 2021; Diterbitkan: Oktober 2021

\section{PENDAHULUAN}


Perkembangan bisnis ritel di Indonesia sudah sangat pesat saat ini. Hal ini ditandai dengan semakin meningkatnya persaingan dalam pembukaan bisnis ritel di berbagai daerah salah satunya adalah Kota Bima. Banyak minimarket yang menyediakan jasa pelayanan dan fasilitas kebutuhan sehari-hari yang sama sehingga menimbulkan persaingan yang ketat. Melihat banyaknya konsumen yang mempunyai keinginan dan kebutuhan yang beragam saat ini, membuat peluang besar bagi para pelaku bisnis untuk mendirikan bisnis ritel modern di kota Bima. Beberapa ritel tersebut diantaranya Hokkymart, Bollymart, Artha Bima Mall dan SMA Yes. Ritel merupakan mata rantai yang penting dalam proses distribusi barang dan merupakan mata rantai terakhir dalam suatu proses distribusi. Industri ritel di Indonesia memberikan kontribusi yang besar terhadap Produk Domestik Bruto (PDB) dan juga menyerap tenaga kerja dalam jumlah yang besar. Sebagai kota yang membangun, angka pertumbuhan ritel di kota Bima dipengaruhi oleh kekuatan daya beli masyarakat, pertambahan jumlah penduduk, dan adanya kebutuhan masyarakat akan pemenuhan produk konsumsi.

Strategi pemasaran sangat dibutuhkan untuk menciptakan keunggulan bersaing bagi perusahaan. Hokkymart dan Bollymart perlu melakukan langkah-langkah yang tepat dalam menetapkan strategi pemasaran dan harus disesuaikan dengan kondisi lingkungan internal yang mencakup kekuatan dan kelemahan perusahaan. Sedangkan ekternal yang mencakup peluang dan ancaman bagi perusahaan.

Berbagai strategi dan ide yang matang harus dimiliki Hokkymart dan Bollymart, misalnya menawarkan produk yang unggul, layanan yang maksimal, mengadakan promosi, bermain harga dan sebagainya.
Konsumen departemen store saat ini lebih selektif memilih produk merek apa yang akan mereka beli, selain melihat dari sisi harga dan sebagainya, merekapun melihat dari segi kualitas produk yang ditawarkan. Hokkymart dan Bollymart memiliki usaha yang sama yaitu bisnis retail. Namun dalam strategi pemasaran Hokkymart dan Bollymart masing-masing mempunyai strategi pemasaran produk.

Dalam menghadapi persaingan industri retail di Kota Bima, beberapa strategi yang digunakan dan telah diterapkan Bollymart dan Hokkymart saat ini diantaranya adalah pemilihan lokasi yag menjangkau masyarakat, promo harga dan produk, kemudahan pembayaran tidak tunai (non-cash), terdapat fasilitas kartu anggota (member) dan penerapan strategi lainnya. Penetapan strategi tersebut merupakan beberapa strategi bersaing Bollymart dan Hokkymart dapat dijadikan sebagai competitive

Bollymart terhadap pesaingnya yaitu Hokkymart.

Namun terlepas dari hal tersebut, permasalahan yang terjadi adalah kurangnya kualitas SDM seperti belum pahamnya terhadap product knowledge dan mekanisme produk-produk promosi yang sedang berjalan, pendistribusian barang ke toko kurang tepat waktu yang mengakibatkan kekosongan barang pada produk tertentu sehingga membuat konsumen kecewa karena beberapa produk yang dicari tidak terdapat pada minimarket tersebut, ketidaksesuain harga di rak display dengan harga di komputer kasir yang disebabkan sistem komputer yang belum update. Kecepatan pelayanan yang masih kurang efektif yang menyebabkan konsumen harus menunggu. Kurangnya fasilitas lahan parkir yang menyebabkan konsumen tidak jadi berkunjung.

Penelitian terdahulu yang dilakukan oleh Siti Karlina, dkk (2020) bahwa 
terdapat perbedaan antara strategi pemasaran promosi pada shopee, bukalapak, lazada, dan tokopedia. Hasil penelitian yang sama pernah dilakukan oleh Syarif Hidayat (2019) bahwa terdapat perbedaan strategi pemasaran Indomaret dengan Alfamart. Strategi pemasaran Alfamart memang layak mendapat ajungan jempol. Mereka berhasil memenangkan hati pelanggannya lewat dukungan TI dan penerapan strategi experiential marketing.

Terlepas dari permasalahan di atas dari hasil penelitian terdahulu dalam penelitian ini ditemukan bahwa dalam pelaksanaan operasionalnya terdapat perbedaan prioritas strategi pemasaran yang diterapkan Bollymart dan Hokkymart. Fenomena lain adalah kualitas sebagian produk yang ditawarkan Hokkymart dan Bollymart beberda. Dari segi harga antara Bollymart dan Hokkymart terdapat perbedaan serta persediaan produk di Bollymart lebih lengkap dari pada Hokkymart. Kenyataan lain bahwa pada saat ini terlihat menonjolnya konsumen pada Bollymart yang lebih ramai dari pada Hokkymart. Hal ini dapat terlihat dari lahan parkir yang selalu penuh oleh kendaraan, dan juga antrian kasir yang memanjang. Hal tersebut disebabkan oleh beberapa hal yaitu keberagaman kebutuhan pada Bollymart yang bervariasi, kualitas pelayanannya yang cukup baik, lahan parkir Bolly yang dinilai memadai, dan Kenyamanan berbeda yang dirasakan konsumen pada Bollymart karena saat ini masyarakat cenderung sudah lebih selektif dalam memilih dan menilai lokasi pasar dimana tempat bagi konsumen tersebut merasa nyaman dan juga kebutuhan-kebutuhan yang dicari oleh konsumen dapat terpenuhi membuat konsumen pada Hokkymart beralih pada Bollymart. Dengan demikian maka tujuan penelitian ini adalah untuk mengetahui dan menganalisis perbedaan strategi pemasaran produk antara Hokkymart dengan Bollymart Kota Bima.

\section{LANDASAN TEORI}

\section{Strategi Pemasaran}

Strategi pemasaran adalah serangkaian tujuan dan sasaran, kebijakan dan aturan yang memberi arah kepada usaha-usaha pemasaran perusahaan dari waktu ke waktu, pada masingmasing tingkatan dan acuan serta alokasinya, terutama sebagai tanggapan perusahaan dalam menghadapi lingkungan dan keadaan persaingan yang selalu berubah. Strategi pemasaran terdiri dari prinsip-prinsip dasar yang mendasari manajemen untuk mencapai tujuan bisnis dan pemasarannya dalam sebuah pasar sasaran, strategi pemasaran mengandung keputusan dasar tentang pemasaran, bauran pemasaran, bauran pemasaran dan alokasi pemasaran, (Kotler dan Keller 2016). Strategi pemasaran adalah rencana untuk memilih dan menganalisis target pasar, mengembangkan, dan memelihara bauran pemasaran yang dapat memuaskan kebutuhan konsumen (Gugup, 2011:232).

Menurut Wahjono, dkk (2018:185) yang dimaksud dengan Strategi Pemasaran ialah mencakup analisis segmentasi pasar dan analisis target pasar. Dalam analisis segmentasi pasar akan dicari jawaban mengenai kemampuan perusahaan dalam menjangkau konsumen, mengidentifikasi konsumen, dan sumber daya yang diperlukan untuk menjangkau dan memuaskan konsumen yang dituju.

\section{Bauran Pemasaran}

Lupiyoadi (2013:92) Bauran pemasaran merupakan perangkat/alat bagi pemasar yang terdiri atas berbagai unsur suatu program pemasaran yang perlu dipertimbangkan agar implementasi 
strategi pemasaran dan penentuan posisi yang ditetapkan dapat berjalan sukses.

Dalam strategi pemasaran sebuah perusahaan atau lembaga untuk mencapai tujuanya maka perlu memperhatikan elemen-elemen dalam strategi pemasaran. Elemen-elemen tersebut menurut Sunyoto (2015) diklasifikasikan sebagai berikut

1. Produk (Product)

Menurut Assauri (2017:200) produk adalah segala sesuatu yang dapat di tawarkan kepada pasar untuk mendapat perhatian, di miliki, di gunakan atau di konsumsi, yang meliputi barang secara fisik, jasa, kepribadian, tempat, organisasi dan gagasan atau buah pikiran.

2. Harga (Price)

Menurut Sumarwan (2015:63) bagi perusahaan, harga adalah suatu nilai tukar dari produk barang maupun jasa yang dinyatakan dalam satuan moneter. Harga juga menggambarkan keseluruhan biaya untuk memproduksi barang dan jasa tersebut serta marjin keuntungan yang diperoleh perusahaan. Bagi konsumen, harga merupakan biaya yang harus dikeluarkan atau dibelanjakan untuk mendapatkan nilai atau manfaat dari barang dan jasa yang dibeli

3. Tempat/Distribusi (Place)

Menurut Tjiptono (2015:345) distribusi adalah berbagai aktifitas pemasaran yang berusaha memperlancar dan mempermudah penyampaian atau penyaluran barang dan jasa dari produsen kepada konsumen, sehingga penggunaanya sesuai dengan yang diperlukan (jenis, jumlah, harga, tempat, dan saat dibutuhkan).

4. Promosi (Promotion)

Menurut Tjiptono \& Chandra (2017:431) promosi merupakan segala bentuk penawaran atau insentif jangka pendek yang ditujukan bagi pembeli, pengecer atau pedagang grosir dan dirancang untuk memperoleh respon spesifik dan segera.

Menurut Soehardi \& Sable, (2019) menguraikan strategis marketing untuk meningkatkan pendapatan usaha mikro, kecil dan menengah adalah sebagai berikut:

1. Kebijakan pemerintah daerah dan pusat dalam mendukung aksesibilitas transportasi udara, laut dan darat seperti pembangunan infrastruktur International Airport and Seaport;

2. Daya tarik daerah tujuan wisata attraktif agar banyak turis domestik dan asing berkunjung ke tempat-tempat pariwisata sehingga produk, jasa dan pendapatan UMKM semakin meningkat;

3. Jejaring media sosial dalam mempromosikan produk dan jasa UMKM;

4. Pemasaran produk dan jasa UMKM melalui smartphone agar lebih efektif dan efisien;

5. Membentuk gugus tugas UMKM terintegrasi atau Integrated Tourism and MSME (Micro, Small and Medium Enterprises) Task Force dalam menyatukan perencanaan, pelaksanaan, pengorganisasian dan monitoring and evaluation;

6. Perlu dukungan Integrated software program yang mengikuti perkembangan new information and communication technology begitu pesat dalam mendukung transaksi pembayaran produk dan jasa bisnis UMKM;

7. Peningkatan kualitas dan kuantitas sumber daya manusia pelaku dan pegawai UMKM yang memiliki kompetensi sertifikasi nasional dan internasional (Soehardi \& Untari, 2020)

8. Kemudahan pelayanan dan Accessability di tempat-tempat Financial technology (Fintech) 


\section{Kerangka Penelitian}

Dalam menghadapi persaingan industri retail di Kota Bima, beberapa strategi yang digunakan dan telah diterapkan Bollymart dan Hokkymart saat ini diantaranya adalah pemilihan lokasi yag menjangkau masyarakat, promo harga dan produk, terdapat fasilitas kartu anggota (member) dan penerapan strategi lainnya. Penetapan strategi tersebut merupakan beberapa strategi bersaing Bollymart dan Hokkymart dapat dijadikan sebagai competitive strategy oleh Bollymart terhadap pesaingnya yaitu Hokkymart. Hokkymart dan Bollymart perlu menyusun strategi pemasaran yang tepat dalam hal ini untuk membentuk keunggulan yang kompetitif. Diharapkan bagi Hokkymart dan Bollymart semakin memperhatikan strategi pemasaran, karena semakin baik strategi pemasaran baik yang dimiliki oleh bisnis retail maka akan dapat bertahan dipangsa pasar yang ada.

Implikasi dari Strategi yang baik bagi toko retail yakni selalu melihat kondisi pasar berpola pada perkembangan masyarakat sekarang ini dan dilakukan secara konfrehensif dan berkesinambungan, karena toko retail berada pada posisi sel pertumbuhan maka perlu meningkatkan strategi yang lebih baik lagi dan jitu (Suhartini. 2012). Untuk memperjelas perbedaan variabel-variabel, berikut ini di kemukakan model penelitian empirik yang mencirmankan alur berfikir dan merupakan dasar bagi perumusan hipotesis, terlihat pada gambar di bawah ini:

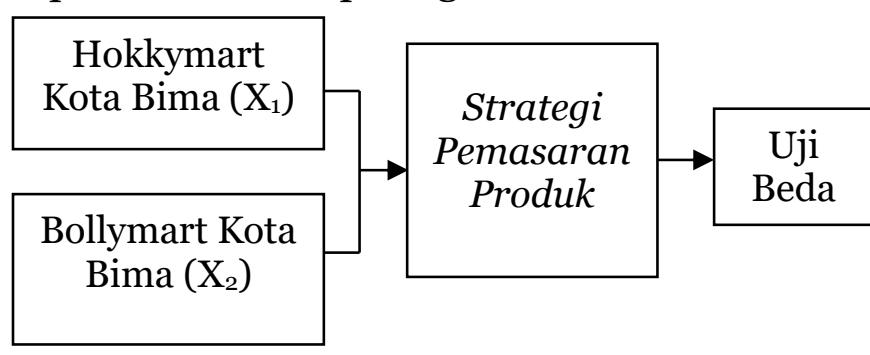

Gambar 1. Kerangka Penelitian

\section{Hipotesis Penelitian}

Hipotesis merupakan dugaan atau jawaban sementara terhadap masalah yang diuji kebenarannya, melalui analisis data yang relevan (Sugiyono, 2014). Berdasarkan teori dan penelitian terdahulu dapat diasumsikan bahwa hipotesis penelitian ini adalah:

Ho : $\mu_{1}=\mu_{2} \quad$ Tidak terdapat perbedaan yang signifikan strategi pemasaran produk antara Hokkymart dengan Bollymart Kota Bima

Ha $: \mu_{1} \neq \mu_{2}$ Terdapat perbedaan yang signifikan strategi pemasaran produk antara Hokkymart dengan Bollymart Kota Bima

\section{METODE PENELITIAN}

Jenis penelitian ini dapat dikategorikan dalam penelitian komparatif, yaitu penelitian yang dilakukan untuk mengetahui nilai variabel mandiri, baik satu variabel atau lebih (independen) yang bersifat membandingkan. Jenis data yaitu kuantitatif dengan sumber data primer. Populasi adalah semua konsumen / pelanggan Hokkymart Kota Bima dengan Bollymart Kota Bima yang jumlahnya tidak bisa diukur (Uknown Population. Sampel pada penelitian ini peneliti memfokuskan untuk memilih sampel konsumen Hokkymart dengan Bollymart. Maka dari itu berdasarkan pendapat Amirullah (2015) menyarankan besarnya sampel penelitian deskriptif komparatif yaitu sebanyak 100150 responden, maka yang akan menjadi sampel dalam penelitian ini adalah berjumlah 200 orang dengan rincian : konsumen Hokkymart 100 orang dan konsumen Bollymart 100 orang. Instrumen penelitian adalah alat yang digunakan dalam melakukan pengumpulan data yang diperlukan dalam suatu penelitian. 
Instrumen pada penelitian ini adalah kuisioner, yaitu sejumlah daftar pertanyaan/pernyataan tertulis yang berisi pertanyaan dengan menggunakan Skala Likert.

Dalam penelitian ini dilakukan analisis dalam beberapa tahap. Tahap yang pertama yaitu uji validitas yang mana untuk menguji validitas dari instrumen penelitian yang digunakan dalam pengumpulan data. Item-item pertanyaan dapat dikatakan valid jika memiliki factor loading lebih dari o,30. Tahap yang kedua yaitu uji reliabilitas yang digunakan untuk mengukur tingkat kepercayaan sebuah instrument penelitian. Dalam penelitian ini, uji reliabilitas dilakukan dengan menggunakan koefisien alpha (a) atau cronbach alpha, dimana dikatakan reliabel jika nilai koefisien lebih dari o,6 menunjukkan tidak adanya interval konsistensi (Ghozali, 2016:46). Tahap ketiga dilakukan uji Statistik. Analisis statistik dan analisis komparatif dengan alat analisis yang digunakan adalah Statistical Package for the Social Sciences (SPSS) versi 23.0 dengan analisis paired $t$ test (Uji t dua sampel berpasangan) dengan probabilitas 5\% (0,05). Menentukan kriteria pengujian dengan membandingkan t-hitung > t-tabel. Jika t-hitung > t-tabel, maka Ho ditolak dan Ha diterima yang menunjukkan terdapat perbedaan yang signifikan strategi pemasaran produk antara Hokkymart dengan Bollymart Kota Bima.

\section{HASIL PENELITIAN PEMBAHASAN}

\section{Analisis Deskriptif}

Berdasarkan olah data hasil SPSS didapatkan demografi responden yang tertera pada tabel 2 sebagai berikut :
Tabel 1 : Profil Responden

\begin{tabular}{cc}
\hline Karakteristik Responden & Porsentase (\%) \\
\hline \multicolumn{2}{c|}{ Jenis Kelamin } \\
\hline Laki-Laki & $37 \%$ \\
Perempuan & $63 \%$ \\
\hline \multicolumn{2}{c|}{ Umur } \\
\hline $31-40$ & $33 \%$ \\
$40-50$ & $41 \%$ \\
$>50 \quad 18 \%$ \\
\multicolumn{2}{c|}{ Status Pekerjaan } \\
\hline Pelajar/Mahasiwa \\
Swasta \\
PNS & $24 \%$ \\
Lainnya & $38 \%$ \\
\hline
\end{tabular}

Sumber : Data Primer diolah Peneliti 2021

Berdasarkan tabel 1 diatas bahwa jumlah responden adalah 100 responden yang mana $37 \%$ berjenis kelamin laki-laki dan $63 \%$ berjenis kelamin perempuan. Pada bagian umur terdapat $33 \%$ berumur $17-30$ tahun, $41 \%$ beerumur $31-40,18 \%$ berumur antara 40-50 dan $8 \%$ berumur $>50$ tahun. Sedangkan informasi status pekerjaan pelajar atau mahasiswa sebanyak 24\%, swasta $38 \%$, PNS $33 \%$ dan lainnya $5 \%$.

\section{Uji Validitas dan Reliabilitas}

Hasil uji validitas untuk instrumen penelitian variabel Strategi Pemasaran Produk Hokkymart Kota Bima dan Strategi Pemasaran Produk Bollymart Kota Bima adalah sebagai berikut :

Tabel 2 : Uji Validitas Strategi Pemasaran Produk

\begin{tabular}{cccc}
\hline No & $\begin{array}{c}\text { r hitung } \\
\text { Variabel X1 }\end{array}$ & $\begin{array}{c}\text { r hitung } \\
\text { Variabel X2 }\end{array}$ & Rxy \\
\hline 1 & 0,653 & 0,531 & Valid \\
\hline 2 & 0,791 & 0,569 & Valid \\
\hline 3 & 0,881 & 0,558 & Valid \\
\hline 4 & 0,894 & 0,521 & Valid \\
\hline 5 & 0,839 & 0,370 & Valid \\
\hline 6 & 0,921 & 0,455 & Valid \\
\hline 7 & 0,881 & 0,460 & Valid \\
\hline 8 & 0,631 & 0,562 & Valid \\
\hline 9 & 0,917 & 0,472 & Valid \\
\hline 10 & 0,907 & 0,526 & Valid \\
\hline
\end{tabular}




\begin{tabular}{cccc}
\hline 11 & 0,677 & 0,305 & Valid \\
\hline 12 & 0,504 & 0,368 & Valid \\
\hline
\end{tabular}

Sumber : Data diolah oleh peneliti dengan SPSS

Dari tabel 2 di atas diketahui bahwa hasil uji validitas Strategi Pemasaran Produk Hokkymart Kota Bima yang disajikan untuk item pertanyaan no. 1-10 diperoleh nilai r-hitung lebih besar dari rpembanding. Dengan demikian seluruh item instrumen pertanyaan penelitian dinyatakan valid/sahih. Sedangkan hasil uji validitas Strategi Pemasaran Produk Bollymart Kota Bima yang disajikan untuk 10 item pertanyaan diperoleh nilai r-hitung lebih besar dari r-pembanding. Dengan demikian seluruh item instrumen pertanyaan penelitian dinyatakan valid/sahih. Ini berarti, tidak ada data yang tidak valid/hilang (missing). Dengan demikian seluruh jumlah indikator dapat digunakan dalam penelitian ini.

Suatu kuisioner dikatakan reliabel atau handal jika jawaban seseorang terhadap pernyataan adalah konsisten atau stabil dari waktu ke waktu. Untuk mengetahui uji ini menggunakan nilai Cronbach Alpha, kuesioner dikatakan reliabel jika nilai dari Cronbach Alpha di atas 0,6o. Hasil uji reliabilitas adalah sebagai berikut :

Tabel 3 : Nilai Reliabilitas

\begin{tabular}{cccc}
\hline Variabel & $\begin{array}{c}\text { Standar } \\
\text { Deviasi }\end{array}$ & $\begin{array}{c}\text { Cronbach } \\
\text { Alpha }\end{array}$ & Keputusan \\
\hline $\begin{array}{c}\text { Strategi } \\
\text { Pemasaran } \\
\text { Produk }\end{array}$ & 0,60 & 0,946 & Reliabel \\
Hokkymart & & & \\
\hline $\begin{array}{c}\text { Strategi } \\
\text { Pemasaran } \\
\text { Produk }\end{array}$ & 0,60 & 0,639 & Reliabel \\
Bollymart & & & \\
Sumber : Data diolah oleh peneliti dengan SPSS
\end{tabular}

Hasil uji reliabilitas variabel Strategi Pemasaran Produk Hokkymart Kota Bima pada tabel 3, diperoleh nilai koefisien Cronbach Alpha sebesar 0,946 yaitu
Cronbach Alpha diatas o,6. Sedangkan hasil koefisien Cronbach Alpha variabel Strategi Pemasaran Produk Bollymart Kota Bima adalah sebesar 0,639 dan Cronbach Alpha lebih besar dari 0,60. Dengan demikian kedua variabel $\mathrm{X} 1$ dan $\mathrm{X} 2$ tersebut dapat dinyatakan reliable. Dengan demikian data yang diperoleh dalam penelitian ini layak digunakan pada analisa selanjutnya.

\section{Analisis Komparatif}

Dari analisis data responden terhadap variabel penelitian yaitu Strategi Pemasaran Produk Hokkymart Kota Bima dengan Strategi Pemasaran Produk Bollymart Kota Bima, maka dapat diketahui bahwa nilai rata-rata paired varians sebagai berikut :

\section{Rata-Rata $X_{1}$ dan $X_{2}$}

Hasil perhitungan nilai rata-rata variabel Strategi Pemasaran Produk Hokkymart Kota Bima dan Strategi Pemasaran Produk Bollymart Kota Bima dengan menggunakan SPSS For Windows V. 23.0 adalah sebagai berikut:

Tabel 4 : Nilai Rata-rata $\mathrm{X}_{1}$ dan $\mathrm{X}_{2}$

Paired Samples Statistics

\begin{tabular}{|c|c|c|c|c|c|}
\hline & & Mean & $\mathrm{N}$ & $\begin{array}{c}\text { Std. } \\
\text { Deviation }\end{array}$ & $\begin{array}{l}\text { Std. Error } \\
\text { Mean }\end{array}$ \\
\hline \multirow[t]{2}{*}{ Pair 1} & $\mathrm{X} 1$ & 43.73 & 100 & 5.550 & .555 \\
\hline & $\mathrm{X} 2$ & 51.76 & 100 & 7.058 & .706 \\
\hline
\end{tabular}

Sumber : Data diolah oleh peneliti dengan SPSS

Dari hail output pada tabel 4 di atas, diketahui nilai rata-rata variabel Strategi Pemasaran Produk Hokkymart Kota Bima adalah sebesar 43,73. Sedangkan nilai ratarata (mean) untuk variabel Bollymart Kota Bima adalah sebesar 51,76. Dari kedua variabel X1 dan X2 tersebut diperoleh nilai rata-rata Strategi Pemasaran Produk Bollymart Kota Bima lebih besar dari pada Strategi Pemasaran Produk pada Hokkymart Kota Bima. 


\section{Simpang Baku Sampel $\left(S_{1}\right)$ dan Simpang Baku $\left(\mathbf{S}_{2}\right)$}

Setelah memperoleh nilai rata-rata masing-masing variabel, maka selanjutnya mencari nilai simpangan baku sampel (S1) dan (S2) dapat dihitung dengan menggunakan SPSS V. 23.0 sebagaimana yang terdapat pada tabel 4.3 di atas dapat diketahui bahwa nilai simpang baku sampel (S1) variabel X1, untuk Strategi Pemasaran Produk Hokkymart Kota Bima adalah sebesar 5,55. Sedangkan nilai simpang baku sampel (S2) variabel $\mathrm{X}_{2}$ untuk Strategi Pemasaran Produk Bollymart Kota Bima adalah sebesar 7,06. dengan demikian dapat disimpulkan bahwa nilai Standar Deviation Strategi Pemasaran Produk Bollymart Kota Bima lebih besar dibandingkan dengan nilai Standar Deviation Strategi Pemasaran Produk Hokkymart Kota Bima

\section{Uji Hipotesis dengan T-Test Paired Varian}

Untuk mengetahui nilai t-sampel dalam penelitian ini, maka digunakan analisis dengan program SPSS V.23.0. Penulis memilih tingkat signifikan adalah $5 \%$ atau a 0,05 . Karena dinilai cukup ketat untuk mewakili perbedaan antara variabel dan merupakan tingkat signifikan yang umum digunakan dalam penelitian. Hasil uji T-Test Paired varian variabel X1 dan X2 adalah sebagai berikut:

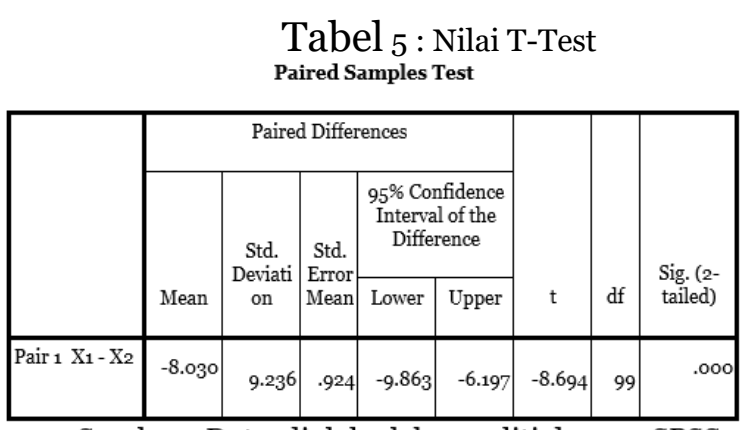

Sumber : Data diolah oleh peneliti dengan SPSS
Berdasarkan hasil analisis t-test paired varian pada output SPSS tabel 5 di atas, menunjukkan bahwa nilai t-hitung adalah sebesar -8,694. Dari hasil uji hipotesis di atas, maka dapat disimpulkan bahwa nilai thitung lebih kecil dari nilai t-tabel ($8,694<1,984)$ dengan nilai sig. $<0,025$ maka $\mathrm{Ha}$ diterima, artinya terdapat perbedaan yang signifikan antara Strategi Pemasaran Produk Hokkymart Kota Bima dengan Bollymart Kota Bima.

Berdasarkan hasil uji Perbandingan (Paired T-test) dapat disimpulkan bahwa Strategi pemasaran produk Bollymart lebih unggul dibandingkan strategi pemasaran Hokkymart atau X2 > X1. Konsumen setuju bahwa strategi pemasaran produk pada masing masing toko retail tersebut berbeda. Dilihat dari kualitas produk antara kedua mini market ini cukup imbang. sama-sama memiliki kualitas produk yang baik, variasi produk yang banyak dan beragam dan sama-sama memiliki fasilitas kartu anggota. Namun dari segi kinerja Bollymart mempunya kinerja baik jika dibandingkan dengan minimarket pesaing utamanya yaitu Hokkymart. Hal ini dapat dilihat dari promo harga dan kelengkapan produk, tempat parkit yang lebih luas, kemudahan pembayaran tidak tunai (non-cash), selain itu sistem distribusi dirancang seefisien mungkin dengan jaringan pemasok yang handal dalam menyediakan produk terkenal dan berkualitas serta sumber daya manusia yang kompeten, menjadikan Bollymart memberikan pelayanan terbaik kepada konsumen

Hasil temuan ini mendukung penelitian yang dilakukan oleh Siti Karlina, dkk (2020) bahwa terdapat perbedaan antara strategi pemasaran promosi pada shopee, bukalapak, lazada, dan tokopedia. Hasil penelitian yang sama pernah dilakukan oleh Syarif Hidayat (2019) bahwa terdapat perbedaan strategi pemasaran 
Indomaret dengan Alfamart. Strategi pemasaran Alfamart memang layak mendapat ajungan jempol. Mereka berhasil memenangkan hati pelanggannya lewat dukungan TI dan penerapan strategi experiential marketing

\section{Kesimpulan}

Berdasarkan hasil penelitian dan uji perbandingan (komparatif) strategi pemasaran produk antara Hokkymart dan Bollymart adalah berbeda baik dari segi segi kinerja Bollymart mempunya kinerja baik jika dibandingkan dengan minimarket pesaing utamanya yaitu Hokkymart, kelengkapan produk variasi produk, promo harga dan, tempat parkit yang lebih luas. Dengan demikian dapat disimpulkan bahwa terdapat perbedaan strategi pemasaran produk pada Hokkymart dengan Bollymart Kota Bima. Strategi pemasaran produk Bollymart lebih unggul dibandingkan strategi pemasaran Hokkymart.

\section{Saran}

Berdasarkan hasil penelitian dan pembahasan serta kesimpulan yang telah dikemukakan, maka penulis memberikan beberapa saran yaitu :

1. Dari segi keberagaman merek produk, sebaiknya Hokkymart terus meningkatkan keberagaman merek produk sehingga produk-produk yang ditawarkan lebih bervariasi dan serta memperluas tempat parkir serta saluran disribusi sehingga mengundang niat konsumen untuk melakukan keputusan pembelian pada Hokkymart Kota Bima

2. Bollymart Kota Bima harus memelihara dengan benar bauran pemasaran yang di sudah di terapkan. Strategi yang digunakan Bollymart sudah baik namun akan lebih baik apabila Bollymart terus meningkatkan strategi - strateginya melihat saat ini sudah banyak kompetitor lain yang bergerak di bidang usaha retail, ini merupakan ancaman bagi perusahaan untuk meningkat penjualan

3. Untuk peneliti selanjutnya diharapkan apabila menggunakan variabel yang sama dengan penelitian ini, agar lebih rinci dan spesifik, serta dalam menentukan indikator setiap variabel menyesuaikan dengan situasi dan kondisi pada objek penelitian. Dan peneliti menyarankan agar dapat menambahkan beberapa variabel yang dapat membedakan strategi pemasaran produk pada diluar variabel yang telah ada di penelitian ini.

\section{DAFTAR PUSTAKA}

Amirullah. (2011). Perilaku Konsumen, Edisi Pertama, Cetakan, Kedua. Penerbit : Graha Ilmu, Yogyakarta.

Abdullah. (2015). Metodologi Penelitian Kuantitatif. Yogyakarta : Aswaja Pressindo

Assauri, S. (2017). Manajemen Pemasaran. Jakarta: PT. Raja Grafindo Persada

Basu Swastha Dharmmesta. 2014. Manajemen Pemasaran. BPFE: Yogyakarta.

Gujarati, Damodar N dan Dawn C. Porter. (2015). Dasar-Dasar Ekonometrika Edisi 5 Buku 2. Jakarta: Salemba Empat.

Ghozali, Imam. (2016). Aplikasi Analisis Multivariete Dengan Program IBM SPSS 23 (Edisi 8). Cetakan ke VIII. Semarang : Badan Penerbit Universitas Diponegoro

Gugup, Kismono. 2011. Bisnis Pengantar. BPFE, Yogyakarta

Lupiyoadi. (2013). Manajemen Pemasaran Jasa Berbasis Kompetensi. Edisi Ketiga.Salemba. Jakarta. 
Kotler dan Keller. (2016). Marketing Management. Edisi Keempat belas Cetakan Pertama. BPFE, Yogyakarta

Prihatini Ade Mayvita1) \& Mohammad Zainul2, (2015). Analisis Strategi Pemasaran Pada Toko Stationery Express Banjarmasin. Al-Ulum Ilmu Sosial Dan Humaniora Volume 1 Nomor 1

Siti Karlina, dkk. (2020). Analisis Perbandingan Strategi Pemasaran Pada Toko Online (Studi Pada Shopee, Bukalapak, Lazada, Dan Tokopedia. Jurnal. Business Management, Economic, and Accounting National Seminar. Volume 1,

Soehardi, \& Sable, S. C. (2019). Strategi

Pemasaran Bisnis Pariwisata di Kota

Davao , Filipina. Jurnal Ilmiah

Manajemen Ubhara, 1(2), 1-13.

https://doi.org/DOI:

http://dx.doi.org/10.31599/jmu.v1i2. 674

Soehardi, S., \& Untari, D. T. (2020). The Effect of Covid-19 Pandemic on Hotel Employees, Hotel Occopancy Rates and Hotel Tax Income in Jakarta, Indonesia. Systematic Reviews in Pharmacy, 11(12), 964-972. https://doi.org/10.31838/srp.2020.5. 138

Sugiyono. (2016). Metode Penelitian Kuantitatif, Kualitatif, dan Kombinasi (Mixed Methods). Bandung : Alfabeta

Sumarwan, Ujang. (2015). Pemasaran Strategik:Prespektif Perilaku Konsumen, dan Marketing Plan. Jakarta: PT. Ghalia Indonesia.

Sunardi dan Anita Primastiwi. (2015). Pengantar Bisnis Konsep, Strategi, \& Kasus. Yogyakarta: Center for Academic Publishing Service.

Suhartini. (2012). Analisis SWOT Dalam Menentukan Strategi Pemasaran Pada Perusahaan. Jurnal Matrik Teknik Industri Univ. Muhammadiyah Gresik. Vol.XII. No.3,
Sunyoto, D. (2015). Strategi Pemasaran. Yogyakarta: CAPS (Center for Academic Publishing Service)

Syarifhidayat. (2019). Perbandingan Strategi Pemasaran yang digunakan antara Minimarket Alfamart dengan Indomart. Jurnal Manajemen.

Tjiptono, Fandi. (2015). Strategi Pemasaran. Yogyakarta. ANDI.

Tjiptono, Fandy., \& Gregorius Chandra. (2017). Pemasaran Strategik. Edisi 3. Yogyakarta: Andi offset

Wahjono, dkk. (2018). Pengantar Bisnis. Jakarta. Kencana 